\title{
Traffic-related exposures and biomarkers of systemic inflammation, endothelial activation and oxidative stress: a panel study in the US trucking industry
}

Andreas M Neophytou ${ }^{1 *}$, Jaime E Hart ${ }^{1,2}$, Jennifer M Cavallari1,3, Thomas J Smith', Douglas W Dockery', Brent A Coull ${ }^{4}$, Eric Garshick ${ }^{2,5}$ and Francine Laden ${ }^{1,2}$

\begin{abstract}
Background: Experimental evidence suggests that inhaled particles from vehicle exhaust have systemic effects on inflammation, endothelial activation and oxidative stress. In the present study we assess the relationships of short-term exposures with inflammatory endothelial activation and oxidative stress biomarker levels in a population of trucking industry workers.

Methods: Blood and urine samples were collected pre and post-shift, at the beginning and end of a workweek from 67 male non-smoking US trucking industry workers. Concurrent measurements of microenvironment concentrations of elemental and organic carbon (EC \& OC), and fine particulate matter $\left(\mathrm{PM}_{2.5}\right)$ combined with time activity patterns allowed for calculation of individual exposures. Associations between daily and first and last-day average levels of exposures and repeated measures of intercellular and vascular cell adhesion molecule-1 (ICAM-1 \& VCAM-1), interleukin 6 (IL-6) and C-reactive protein (CRP) blood levels and urinary 8-Hydroxy-2'-Deoxyguanosine $(8-\mathrm{OHdG})$ were assessed using linear mixed effects models for repeated measures.

Results: There was a statistically significant association between first and last-day average $\mathrm{PM}_{2.5}$ and 8-OHdG (21\% increase, 95\% Cl: 2, 42\%) and first and last-day average OC and IL-6 levels (18\% increase 95\% Cl: 1, 37\%) per IQR in exposure. There were no significant findings associated with EC or associations suggesting acute cross-shift effects.
\end{abstract}

Conclusion: Our findings suggest associations between weekly average exposures of $\mathrm{PM}_{2.5}$ on markers of oxidative stress and OC on IL-6 levels.

Keywords: Particulate matter, Elemental carbon, Organic carbon, ICAM-1, VCAM-1, IL-6, CRP, Inflammation, Endothelial activation, Trucking industry

\section{Background}

Vehicle exhaust related particulate air pollution has been associated with cardiovascular health outcomes, including, ventricular arrhythmias, onset of myocardial infarction and increased cardiovascular mortality [1-7], while occupational exposures to vehicle exhaust also have been shown to be associated with ischemic heart disease $[8,9]$.

\footnotetext{
* Correspondence: aneophyt@hsph.harvard.edu

${ }^{1}$ Exposure Epidemiology and Risk Program, Department of Environmental Health, Harvard School of Public Heath, Boston, MA, USA

Full list of author information is available at the end of the articlel
}

We have previously observed an increased risk of ischemic heart disease mortality in US trucking industry workers with regular exposures to exhaust from diesel, gasoline and propane source [10]. Occupational air pollution exposures in the trucking industry are relevant to the general population due to overlap with levels experienced during daily activities such as commuting [11,12].

Potential pathways for these outcomes include systemic inflammation, endothelial dysfunction and oxidative stress, which experimental animal and human studies suggest are associated with traffic-related particulate matter (PM)

\section{Biomed Central}

(c) 2013 Neophytou et al.; licensee BioMed Central Ltd. This is an open access article distributed under the terms of the Creative Commons Attribution License (http://creativecommons.org/licenses/by/2.0), which permits unrestricted use, distribution, and reproduction in any medium, provided the original work is properly cited. 
[13-20]. Associations between markers of cellular damage and induction of inflammatory responses and oxidative stress, however, are not adequately defined and have not been well characterized in a population with vehicle exhaust exposures in a non-experimental setting.

Previous studies have shown associations between biomarkers of endothelial function such as transmembrane proteins intercellular adhesion molecule-1 (ICAM-1) and vascular cell adhesion molecule-1 (VCAM-1), and air pollution exposures [21]. ICAM-1 and VCAM-1 levels are associated with increased cardiovascular risk and are predictors of acute coronary events [22-24]. General markers of inflammation like interleukin-6 (IL-6) and C-reactive protein (CRP) have also been associated with cardiovascular risk $[25,26]$ and air pollution $[27,28]$. In addition, CRP has recently been linked to cancer mortality in general and lung cancer incidence in particular $[29,30]$. Urinary 8-Hydroxy-2' Deoxyguanosine (8-OHdg) is a DNA lesion repair product [31], suitable as an oxidative damage biomarker that has also been shown to be associated with particulate exposures $[15,32,33]$.

The current study characterizes exposures to different components of engine exhaust in a sample of workers in the trucking industry and examines the relation between exposure and inflammation, endothelial activation, and oxidative stress as indicated by plasma levels of IL-6, CRP, ICAM-1 and VCAM-1 and by urinary levels of $8-\mathrm{OHdG}$ from repeated blood and urine samples, sampled over the duration of one work-week. The study examines associations over different time-windows for both acute and more intermediateterm effects.

\section{Methods}

\section{Study population}

We studied a sample of 95 workers originated from 10 work locations (truck terminals) in the northeastern US (specifically CT, MA, MD, NJ, NY, and PA). Primary analyses were restricted to non-smoking males with biological samples who did not report sick days during the sampling period $(n=67)$. Measurements took place between February 2009 and October 2010, with terminals sampled one at time for up to 8 days of continuous sampling. Subjects were selected from 3 different job categories representing different exposure scenarios: pick-up and delivery (P\&D) drivers, freight dockworkers and office clerks. Participants provided informed consent and were compensated at the end of the protocol for their participation. The protocol was approved by the Institutional Review Board of the Brigham and Women's Hospital and the Human Subjects Committee of the Harvard School of Public Health.

\section{Microenvironment exposure measurements}

Microenvironment area samples of $\mathrm{PM}_{2.5}$ (particulate matter with a diameter of $\leq 2.5 \mu \mathrm{m}$ ), as well as elemental carbon (EC) and organic carbon $(\mathrm{OC})$ in $\mathrm{PM}_{1.0}$ (particulate matter with a diameter of $\leq 1.0 \mu \mathrm{m}$ ) were collected from all 10 terminals in the study. Twelve-hour integrative area samples were collected indoors in office spaces and terminal docks 24 hours a day. For the P\&D drivers, samplers were placed in their truck cabs for the duration of each work-shift on the days of biological sample collection. Detailed exposure assessment for each of the three pollutants is described elsewhere [11]. Briefly EC and $\mathrm{OC}$ were measured by collecting $\mathrm{PM}_{1.0}$ on a $22-\mathrm{mm}$ quartz tissue filter, preceded by a precision machined cyclone separator (SCC1.062 Triplex, BGI, Inc., Waltham, MA), which was then analyzed by thermal-optical carbon analyzer using the NIOSH 5040 method [34]. $\mathrm{PM}_{2.5}$ was collected on a $37-\mathrm{mm}$ Teflon filter (with a pore diameter of $2.0 \mu \mathrm{m}$ ) after passing through a precision-machined cyclone pre-selector to remove particles greater than $2.5 \mu \mathrm{m}$ aerodynamic diameter. The method was consistent with the EPA PQ200 Federal Reference Method [35,36]. A flow rate of 3.5 liters per minute was used for both $\mathrm{PM}_{2.5}$ and $\mathrm{PM}_{1.0}$ samples. Exposures were assigned to each individual participant as a weighted average of the time spent in each work location based on the samples in each location during each work shift.

\section{Biomarker sampling}

During each truck terminal visit, initial blood samples were drawn and urine was collected from study participants prior to the day's work shift on their first day back to work after at least 2 days off. At the end of the first work shift a second blood and urine sample were collected and then pre- and post-shift samples were collected again on the last workday of the same week. At each blood draw, two 10-ml liquid EDTA blood tubes were drawn and stored at $4^{\circ} \mathrm{C}$ until shipped in an insulated container to our blood processing laboratory where they were centrifuged, aliquoted and stored in the vapor phase of liquid nitrogen freezers at $<-130^{\circ} \mathrm{C}$. Up to $50 \mathrm{ml}$ of urine were collected in a sterile urine cup at each sampling period and stored at $4^{\circ} \mathrm{C}$ until returned to the study laboratory, where they were kept at $-20^{\circ} \mathrm{C}$ until analysis.

Analysis of CRP, IL-6, ICAM-1 and VCAM-1 was done at the Clinical and Epidemiologic Research Laboratory, Department of Laboratory Medicine at Children's Hospital in Boston, a state-of the-art laboratory specializing in micro-analysis. The stability of the selected biomarkers was assessed by processing at 0,24 and 36 hours after packaging and storage on ice in a shipping container and there were no differences in the measured marker levels [37]. 
CRP concentrations were determined with the use of a high sensitivity immonoturbidimetric assay, with a sensitivity of $0.03 \mathrm{mg} / \mathrm{L}$. Values of CRP $>10 \mathrm{mg} / \mathrm{L} \quad(\mathrm{n}=3)$ were excluded from the analysis as they suggest elevation due to recent acute illness. IL-6, ICAM-1 and VCAM-1 were measured using ELISA assays with sensitivities of $0.094 \mathrm{pg} / \mathrm{mL}, 0.35 \mathrm{ng} / \mathrm{mL}$ and $0.6 \mathrm{ng} / \mathrm{mL}$, respectively. Urinary $8-\mathrm{OHdG}$ levels were measured in the laboratory of Dr. Junfeng Zhang at the University of Southern California using a high performance liquid chromatography with electrochemical detection (HPLC-ECD) method with a level of detection (LOD) of $0.46 \mathrm{ng} / \mathrm{mL}$. Urinary creatinine was also measured and 8-OHdG levels were corrected and reported as $\mu \mathrm{g} / \mathrm{g}$ creatinine. Three subjects contributed no or insufficient blood sample volumes for analysis on at least one measurement occasion and analysis was restricted to the remaining occasions for these individuals. None of the analyzed samples were below the stated LODs.

\section{Health and personal habit assessment}

A baseline medical and health questionnaire based on the American Thoracic Society adult respiratory questionnaire [38] was administered to all participants. The questionnaire included standardized questions regarding respiratory symptoms and conditions, and was supplemented with questions about other medical conditions such as heart disease, cancer, and diabetes. Information was also provided on job title and job history, date and time of last work shift, past week work schedule, terminal assignment, specific duties, recent acute illnesses, and lifestyle characteristics such as physical activity and smoking history. A personal habits portion of the questionnaire including medication use (such as aspirin, blood pressure medications and lipid lowering agents), smoking, and second hand smoke (SHS) exposure as well as information on job duties during the day, and timing and location of all breaks, was administered at the end of each shift during the work week. Weight and height were measured by the study team to calculate body mass index (BMI).

\section{Statistical analyses}

Marker levels were natural log-transformed and proportional changes are reported. Linear mixed effects models for repeated measures with unstructured autocorellation, were used to estimate the effects each of the measured pollutants on marker levels for all study participants in the primary analysis study population. We included a random intercept for each participant to account for baseline inter-individual differences. Personal characteristics including known predictors of CRP, IL-6, ICAM-1 and VCAM-1 such as age, BMI, physician diagnosed hypertension, physical activity, chronic disease, and medication use were included as confounders $a$ priori in the models. Models for 8-OHdG included age, BMI, physical activity, diabetes, and chronic respiratory conditions, which are thought to be associated with oxidative damage $[39,40]$. Additional covariates such as terminal (accounting for possible seasonal and regional differences), past smoking history, self reported SHS exposures during the work shift, and switching shifts were also considered as potential confounders and were kept in the models if they changed the primary effect estimate by $\geq 10 \%$. The models fitted were as follows:

$$
\begin{aligned}
Y_{i j k}=\beta_{0} & +\beta_{1}\left(\text { Exp }_{i}+\beta_{2}(\text { day })_{j}+\beta_{3}(\text { shift })_{k}\right. \\
& +\beta_{4}\left(\text { day }{\text { shift })_{j k}+\gamma(\text { covariates })_{i j k}}\right. \\
& +b_{i}+\varepsilon_{i j k}
\end{aligned}
$$

where:

- $\mathrm{Y}_{\mathrm{ijk}}$ : log-transformed marker levels for subject $\mathrm{i}$, on day $j$, at the $k$ (pre-or post-shift) measurement point

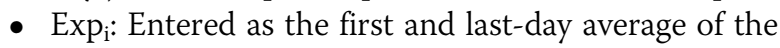
daily pollutant levels on the two measured workshifts

- Day : Measurement day j: first or last day worked during the week

- Shift $_{\mathrm{k}}$ : Measurement time k relevant to shift: pre- or post-shift

- Covariates $\mathrm{ijk}_{\mathrm{k}}$ : Covariates entered in the model depending on biomarker of interest as listed above.

- $\mathrm{b}_{\mathrm{i}}$ : random intercept for each individual $\mathrm{i}$

- $\varepsilon_{\mathrm{ijk}}$ : within subject error

The average exposure model was fitted to examine possible effects that persist rather than being acute. The day and shift variables and their interaction allow outcome measurements to vary with time irrespective of exposure or covariate values. To examine for any transient effects the following model was fitted:

$$
\begin{aligned}
Y_{i j}=\beta_{0} & +\beta_{1}(\operatorname{Exp})_{i j}+\beta_{2}(\text { day })_{j}+\gamma(\text { covariates })_{i j} \\
& +b_{i}+\varepsilon_{i j}
\end{aligned}
$$

Using only post-shift measurements where $\operatorname{Exp}_{\mathrm{ij}}$ is the estimated daily exposure for each participant on a given day, and the other variables are as described above.

In the case of statistically significant findings, multipollutant models were fitted. Models with penalized spline terms instead of linear terms for exposures were fitted to examine the shape of dose-responses. Finally, exposure time (day and shift) interactions were also included and the choice of the final model was decided by likelihood ratio tests. Statistical analysis was performed using the SAS mixed procedure (SAS version 9.3; SAS Institute Inc., Cary, NC) and penalized spline models were fitted using the $R$ mgcv package ( $R$, version 2.15.2). 
Table 1 Study population baseline characteristics in a sample of male, non-smoking trucking industry workers

\begin{tabular}{|c|c|c|c|c|}
\hline & Total & P\&D driver & Dock & Office \\
\hline Total no. & 67 & 35 & 14 & 18 \\
\hline \multicolumn{5}{|l|}{ Race (no. (\%)) } \\
\hline White & $62(93 \%)$ & $32(91 \%)$ & $14(100 \%)$ & $16(89 \%)$ \\
\hline Hispanic & $5(7 \%)$ & $3(9 \%)$ & $0(0 \%)$ & $2(11 \%)$ \\
\hline Age (years, mean $\pm S D$ ) & $50.4 \pm 8.5$ & $51.1 \pm 7.8$ & $47.9 \pm 11.0$ & $50.8 \pm 7.5$ \\
\hline $\mathrm{BMI}\left(\mathrm{kg} / \mathrm{m}^{2}\right.$, mean $\left.\pm \mathrm{SD}\right)$ & $30.4 \pm 4.4$ & $30.8 \pm 4.1$ & $29.8 \pm 4.3$ & $30.1 \pm 5.2$ \\
\hline Past smoker (no. (\%)) & $36(54 \%)$ & $23(66 \%)$ & $6(43 \%)$ & 7 (39\%) \\
\hline Exercise (hrs/wk, mean \pm SD) & $3.3 \pm 3.7$ & $2.3 \pm 2.9$ & $4.6 \pm 5.4$ & $4.4 \pm 2.7$ \\
\hline Hypertension (no. (\%)) & $24(36 \%)$ & $13(37 \%)$ & $6(43 \%)$ & $5(28 \%)$ \\
\hline Heart disease (no. (\%)) & $3(4 \%)$ & $0(0 \%)$ & $1(7 \%)$ & $2(11 \%)$ \\
\hline CHD (no. (\%)) & $6(9 \%)$ & $4(11 \%)$ & $1(7 \%)$ & $1(6 \%)$ \\
\hline Diabetes (no. (\%)) & $1(1.5 \%)$ & $1(3 \%)$ & $0(0 \%)$ & $0(0 \%)$ \\
\hline \multicolumn{5}{|l|}{ Medication use } \\
\hline Blood pressure & $19(28 \%)$ & $9(26 \%)$ & $5(36 \%)$ & $5(28 \%)$ \\
\hline Lipid lowering & $24(36 \%)$ & $14(40 \%)$ & $4(29 \%)$ & $6(33 \%)$ \\
\hline Aspirin & $17(25 \%)$ & $9(26 \%)$ & $2(14 \%)$ & $6(33 \%)$ \\
\hline Total workdays (mean \pm SD) & $4.0 \pm 0.5$ & $3.9 \pm 0.4$ & $4.4 \pm 0.5$ & $3.9 \pm 0.5$ \\
\hline Avg shift duration (hrs, mean \pm SD) & $9.5 \pm 1.8$ & $10.6 \pm 1.0$ & $8.6 \pm 1.6$ & $8.1 \pm 1.9$ \\
\hline Total hrs worked during study period & $45.8 \pm 9.4$ & $50.7 \pm 6.9$ & $41.7 \pm 9.3$ & $39.3 \pm 8.8$ \\
\hline
\end{tabular}

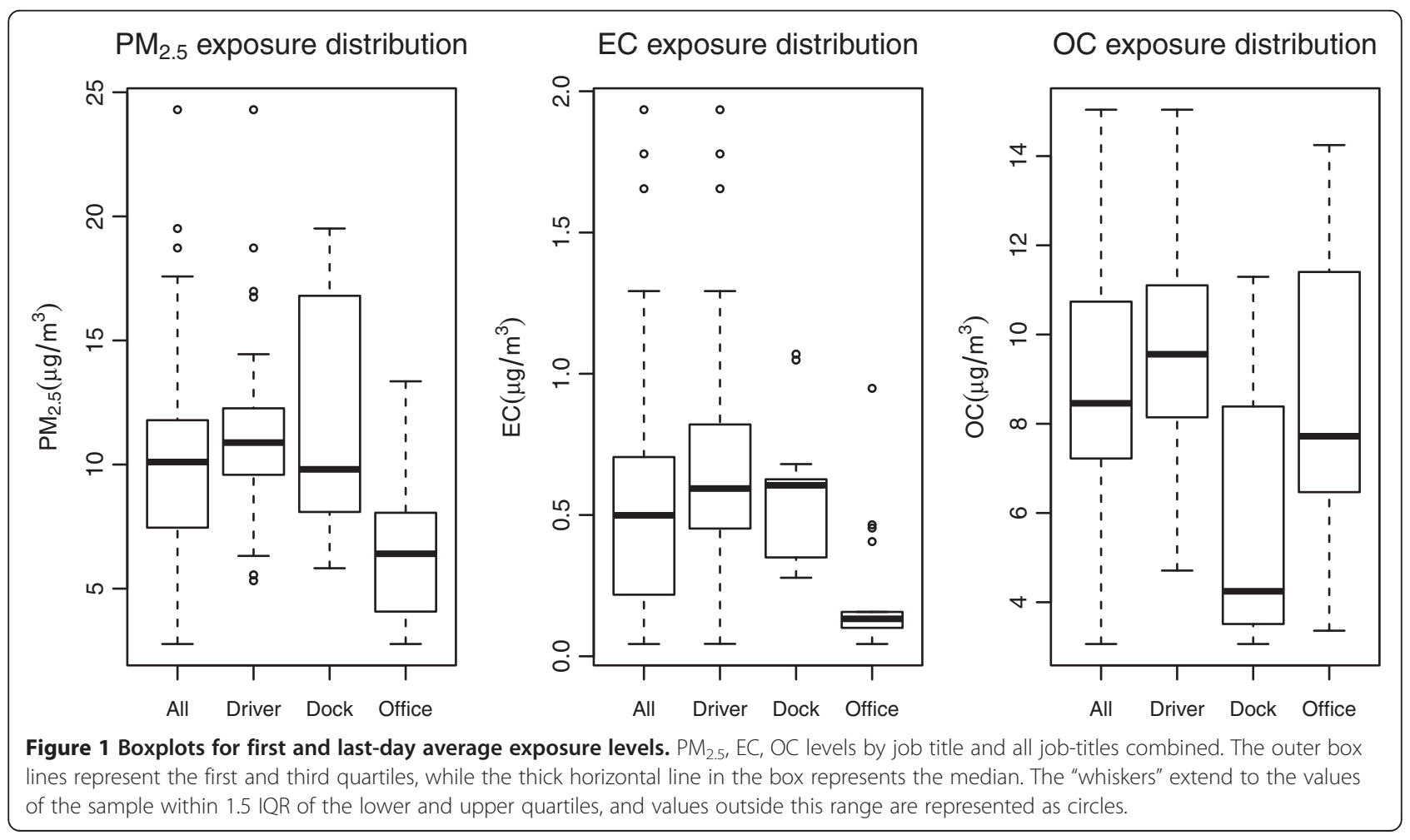




\section{Results}

\section{Study population}

Descriptive statistics for the participants in the primary analysis are presented in Table 1 collectively and by job title. Briefly, the study sample was predominantly white (93\%), while the age range was 23 to 66 years, with a mean \pm standard deviation (SD) of $50.4 \pm 8.5$. The range for the length of the workweek among study participants was 2 to 5 days with a mean of 4 days. The range of shift length was 2.2 to 13.4 hours with a mean of 9.5 hours per shift and an average of 45.8 hours worked during the week, with drivers working longer hours that the other two job groups. Overall this was a healthy working population except for elevated BMI levels (mean BMI was $30.4 \pm 4.4$ ), with few reports of chronic disease. Twenty-four (36\%) participants reported use of lipid lowering agents and nineteen (28\%) reported use of blood pressure medication. Study participants appeared to be similar across job titles with the exceptions that
P\&D Drivers were more likely to be ex-smokers. OneWay Analysis of Variance indicated significant differences across job title levels in only the means of length of work week and total hours worked out of all covariates presented (p-value for F-test $<0.01$ for both).

\section{Exposure measurements}

Estimated individual exposure levels are presented in Figure 1. Overall first-and-last-day average $( \pm$ SD) levels for the three pollutants examined were $10.22( \pm 4.30)$ $\mu \mathrm{g} / \mathrm{m}^{3}$ for $\mathrm{PM}_{2.5}, 0.54( \pm 0.40) \mu \mathrm{g} / \mathrm{m}^{3}$ for EC and 8.60 $( \pm 2.91) \mu \mathrm{g} / \mathrm{m}^{3}$ for OC. Dockworkers and P\&D drivers had higher $\mathrm{PM}_{2.5}$ and $\mathrm{EC}$ exposures compared to office clerks, while $\mathrm{OC}$ was highest among $\mathrm{P} \& \mathrm{D}$ drivers followed by office clerks. Correlations between average exposures were not high with pearson coefficients of 0.370 between $\mathrm{PM}_{2.5}$ and EC, 0.344 between $\mathrm{PM}_{2.5}$ and EC, and 0.004 between EC and OC. One-Way Analysis of Variance indicated significant differences for the

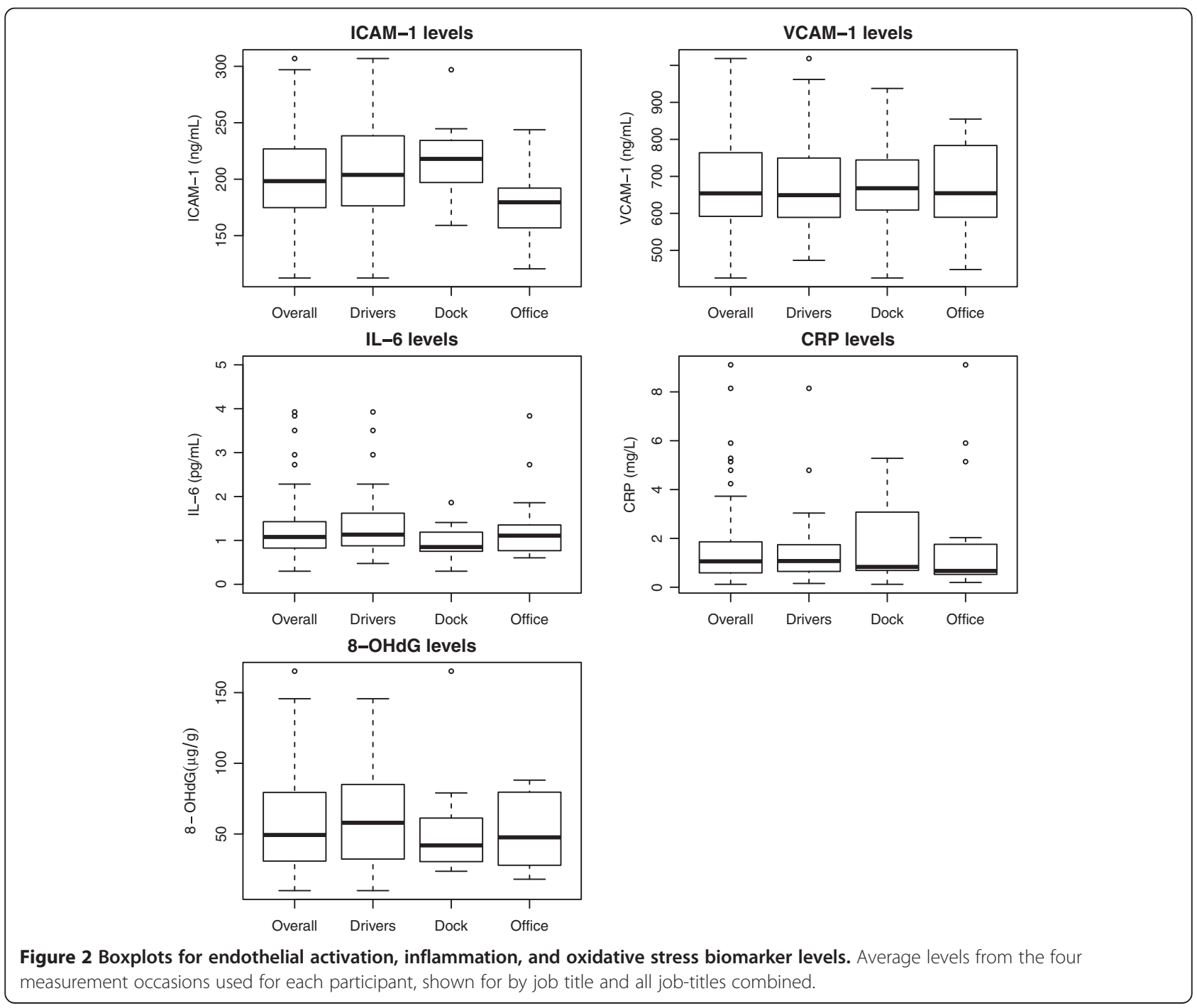


Table 2 Mean ( \pm SD) and geometric mean ( \pm GSD) for subject specific mean marker levels averaged over the 4 different measurement points

\begin{tabular}{|c|c|c|c|c|c|c|c|c|}
\hline \multirow[t]{2}{*}{ Biomarker } & \multicolumn{2}{|c|}{ Overall } & \multicolumn{2}{|c|}{ P\&D drivers } & \multicolumn{2}{|c|}{ Dockworkers } & \multicolumn{2}{|c|}{ Office clerks } \\
\hline & Mean $( \pm$ SD) & $\overline{G M}( \pm \mathrm{GSD})$ & Mean ( \pm SD) & $\overline{\mathrm{GM}}( \pm \mathrm{GSD})$ & Mean $( \pm$ SD) & $\overline{\mathrm{GM}( \pm \mathrm{GSD})}$ & Mean $( \pm$ SD) & $\overline{\mathrm{GM}( \pm \mathrm{GSD})}$ \\
\hline ICAM-1 (ng/mL) & $202 \pm 40$ & $198 \pm 1.22$ & $208 \pm 42$ & $203 \pm 1.23$ & $216 \pm 34$ & $213 \pm 1.17$ & $181 \pm 32$ & $178 \pm 1.19$ \\
\hline VCAM-1 (ng/mL) & $677 \pm 131$ & $661 \pm 1.21$ & $679 \pm 144$ & $663 \pm 1.23$ & $673 \pm 123$ & $658 \pm 1.21$ & $675 \pm 115$ & $661 \pm 1.19$ \\
\hline IL-6 (pg/mL) & $1.38 \pm 1.20$ & $1.09 \pm 1.71$ & $1.36 \pm 0.79$ & $1.12 \pm 1.59$ & $1.50 \pm 2.17$ & $0.98 \pm 2.14$ & $1.30 \pm 0.82$ & $1.11 \pm 1.61$ \\
\hline CRP (mg/L) & $1.66 \pm 1.80$ & $1.00 \pm 2.63$ & $1.53 \pm 1.51$ & $1.01 \pm 2.36$ & $1.72 \pm 1.68$ & $0.98 \pm 3.18$ & $1.87 \pm 2.41$ & $1.01 \pm 2.90$ \\
\hline 8-OHdG ( $\mu \mathrm{g} / \mathrm{g}$ creat.) & $55.9 \pm 31.5$ & $47.7 \pm 1.79$ & $58.9 \pm 32.9$ & $49.3 \pm 1.90$ & $52.8 \pm 36.1$ & $45.8 \pm 1.67$ & $52.3 \pm 25.4$ & $46.0 \pm 1.72$ \\
\hline
\end{tabular}

means all three pollutants across the different job title levels ( $\mathrm{p}$-value for F-test $<0.001$ for all three pollutants).

\section{Associations between biomarker levels and exposures}

From the 67 participants, a total of 264 blood (ICAM-1, VCAM-1, IL-6, CRP) and 268 urine samples (8-OHdG) were analyzed. The distributions of subject specific mean biomarker levels are shown in Figure 2, while mean $( \pm S D)$, medians, geometric means (GM) and geometric standard deviations (GSD) are summarized in Table 2 (Presented here as the average of four collection time points for descriptive purposes; biomarker measurements were entered individually in all models considered). For the endothelial activation markers, there was little difference in the means by job title for VCAM-1, but mean ICAM-1 levels were higher among P\&D drivers and dockworkers compared to office clerks ( $\mathrm{p}$-value for One-Way Analysis of Variance F-Test, $\mathrm{p}=0.03)$. However, neither ICAM-1 nor VCAM1, were associated with $\mathrm{PM}_{2.5}$, EC, and OC levels for either the average (Table 3 ) or daily shift exposures (Table 4).

Little difference was seen in inflammation (CRP, IL-6) biomarker levels across job titles (Table 2). No associations with any of the pollutant exposures were seen for CRP, but a statistically significant association between IL-6 and first and last-day average OC levels was observed $(17.7 \%$ increase per IQR in exposure, 95\% CI: 1.2 , $36.9 \%)$ (Table 3). The OC effect size (18.7\%, 95\% CI: 0.7, $39.8 \%)$ was stable in the multi-pollutant model, where first and last-day average $\mathrm{PM}_{2.5}$ and $\mathrm{EC}$ were included at the same time (Table 5). No significant associations were observed between any of the daily exposures and inflammation marker levels (Table 4).
Mean 8-OHdG levels were similar among all job titles (Table 2). However, there was a statistically significant increase in 8-OHdG levels associated with each IQR increase in first and last-day average $\mathrm{PM}_{2.5}(20.6 \%, 95 \% \mathrm{CI}$ : $2.4,42.0 \%$ ) (Table 3). The $\mathrm{PM}_{2.5}$ effect size (16.7\%, 95\% CI: $-3.3,40.9 \%)$ remained elevated though not statistically significant in the model that included all three pollutants (Table 5). Again, no significant associations were observed between any of the daily exposures and 8-OHdG (Table 4).

No exposure time interactions were statistically significant; therefore, they were not included in the primary models for any of the biomarkers considered. The final models also included all covariates that were added $a$ priori and self reported SHS exposure. Penalized spline models (Figure 3) indicated that there were no statistically significant deviations from linearity.

\section{Discussion}

Overall our findings suggest average (calculated as the mean of two measurement days) but not daily effects of traffic related exposures on biomarkers of oxidative stress and inflammation. Specifically, we observed a statistically significant association between average $\mathrm{PM}_{2.5}$ levels and urine levels of the oxidative damage marker 8-OHdG. Although exposure data were not available for all work shifts during the complete work-week, this finding was consistent in direction and magnitude with reported increases of $8-\mathrm{OHdG}$ associated with a 7-day moving average of ambient $\mathrm{PM}_{2.5}$ levels in an elderly population [15]. The same study reports an even greater increase with 21-day moving averages indicating a

Table 3 Percent change and 95\% confidence intervals in biomarker levels associated with each IQR increase in average exposure levels ${ }^{\mathrm{a}}$

\begin{tabular}{lcccccc}
\hline Exposure $^{\text {b }}$ & IQR & ICAM-1 & VCAM-1 & IL-6 & CRP & 8-OHdG \\
\hline PM $_{2.5}$ & 4.59 & $3.5(-1.1,8.4)$ & $0.4(-4.3,5.4)$ & $3.3(-8.6,16.7)$ & $-6.3(-25.1,17.3)$ & $20.6(2.4,42.0)$ \\
EC & 0.51 & $-1.2(-6.8,4.6)$ & $-1.7(-7.4,4.3)$ & $-3.1(-16.7,12.8)$ & $-15.0(-35.6,12.2)$ & $17.5(-4.6,44.7)$ \\
OC & 3.62 & $-2.2(-7.8,3.8)$ & $2.4(-3.6,8.9)$ & $17.7(1.2,36.9)$ & $4.1(-21.9,38.8)$ & $10.4(-11.3,37.4)$ \\
\hline
\end{tabular}

Notes: ${ }^{a}$ Linear mixed effect models for repeated measures using all 4 measurements per participant, with random intercepts for each individual and adjusting for age, BMI, physical activity, hypertension, chronic disease, SHS exposure and in the case of inflammation and endothelial activation markers time varying medication use.

${ }^{b}$ Pollutant models with first and last-day average exposure values (average of available daily exposures over the work-week) as the exposure of interest, with each pollutant modelled separately. 
Table 4 Percent change and 95\% confidence intervals in biomarker levels associated with each IQR increase in daily exposure levels ${ }^{\mathrm{a}}$

\begin{tabular}{lcccccc}
\hline Exposure $^{\mathbf{b}}$ & IQR & ICAM-1 & VCAM-1 & IL-6 & CRP & 8-OHdG \\
\hline PM $_{2.5}$ & 6.11 & $-1.1(-3.7,1.5)$ & $-1.8(-4.2,0.7)$ & $2.2(-7.6,13.0)$ & $-0.2(-13.1,14.8)$ & $8.9(-6.5,26.5)$ \\
EC & 0.56 & $0.1(-2.5,2.8)$ & $-0.3(-2.8,2.3)$ & $-7.1(-14.6,1.0)$ & $-5.3(-13.7,4.0)$ & $4.9(-9.3,21.3)$ \\
OC & 3.97 & $-1.1(-4.4,2.2)$ & $-1.1(-4.3,2.1)$ & $12.2(-0.4,25.8)$ & $1.2(-14.7,20.0)$ & $-3.1(-18.7,15.4)$
\end{tabular}

Notes: ${ }^{a}$ Linear mixed effect models for repeated measures using only the 2 post-shift measurements per participant, with random intercepts for each individual and adjusting for age, BMI, physical activity, hypertension, chronic disease, SHS exposure and in the case of inflammation and endothelial activation markers time varying medication use.

${ }^{\mathrm{b}}$ Pollutant models with daily exposure values as the exposure of interest, with each pollutant modelled separately.

greater longer-term effect, and also positive effects for OC, but not for EC. In our study, effect estimates for $\mathrm{EC}$ and $\mathrm{OC}$ were also positive, but not statistically significant.

We observed a statistically significant increase in IL-6 associated with average $\mathrm{OC}$, but not with other air pollutant measures. This association remained statistically significant even after controlling for other pollutants. Three and five-day moving averages of primary $\mathrm{OC}$ in PM exposure effects on IL-6 blood levels in elderly susceptible populations have also been reported in previous studies and appeared more pronounced than 1-day moving average exposures [41]. This would suggest a more gradual inflammatory response as compared to an acute effect. While the study populations may not be necessarily comparable, in our study, neither the effect estimates for daily exposures nor any exposure-time interactions were statistically significant, which may be a further indication that any exposure effects may accumulate over longer time windows than were assessed here. Given that this a chronically exposed population, it is possible that there is a longer lasting effect on biomarker levels and no apparent washout over the space of two days off work. Unfortunately in the present study, we lacked the data to be able to address this issue.

A number of general population studies have not shown relationships between air pollution and inflammatory markers. Specifically, studies examining PM and CRP and IL-6 levels in healthy individuals saw no significant associations [42-44]. There is evidence; however, of

Table 5 Percent change and $95 \%$ confidence intervals of IL-6 and 8-OHdG levels associated in multi-exposure models of first and last-day average exposures ${ }^{a}$

\begin{tabular}{lcc}
\hline Exposure $^{\mathbf{b}}$ & IL-6 & 8-OHdG \\
\hline $\mathrm{PM}_{2.5}$ & $-0.6(-13.4,14.0)$ & $16.7(-3.3,40.9)$ \\
EC & $-4.4(-18.3,11.9)$ & $9.1(-12.4,36.0)$ \\
OC & $18.7(0.7,39.8)$ & $2.2(-18.5,28.2)$ \\
\hline
\end{tabular}

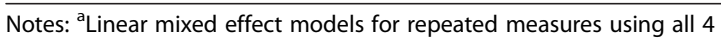
measurements per participant, with random intercepts for each individual and adjusting for age, BMI, physical activity, hypertension, chronic disease, SHS exposure and in the case of IL- 6 time varying medication use.

${ }^{\mathrm{b}}$ Models included first and last-day-average values for $\mathrm{PM}_{2.5}, \mathrm{EC}$ and $\mathrm{OC}$ in the same model. greater susceptibility in certain individuals such as those with coronary heart disease or diabetes [28,42]. CRP levels measured 10-14 hr after the work-shift in North Carolina State Troopers studied over 4-days, were associated with $\mathrm{PM}_{2.5}$ levels in their patrol cars [45], but to our knowledge those results have not been reproduced. Overall findings on the association between CRP and PM exposures in particular have been mixed with a number of studies, including randomized crossover trials, reporting no significant associations between PM concentrations and CRP levels [46].

Our results concerning endothelial activation (ICAM-1 and VCAM-1) did not yield any statistically significant findings. Modest increases associated with ambient $\mathrm{PM}_{2.5}$ have been reported for these markers in an elderly population, again more pronounced when 7-day or longer moving averages of exposure were considered compared to shorter periods [47]; however, our study was not designed to detect associations with averaging periods of that length. Previous studies have also shown acute increases in ICAM-1 and VCAM-1 in bronchial tissue and mucosa in healthy volunteers exposed to diesel particles in experimental settings, but at much higher exposure levels than the ones observed in this study. Furthermore, those volunteers were not chronically exposed [17,48]. Associations between VCAM-1 levels and 2-day average black carbon $(\mathrm{BC})$ exposures have also been reported [49], as well as between longer $\mathrm{BC}$ exposure averages (4-12 weeks) and ICAM-1 [21], and lastly 1-2 day lagged associations between EC and ICAM-1 in coronary heart disease patients [16]. We found no evidence of associations between EC and these endothelial activation markers in our time windows.

Trucking industry and highway exposures have decreased in recent years, as a result of recent emissions regulations [50]. The low levels of exposures observed in the current study may have been a reason for the lack of additional significant findings. Another limitation of this study is that the sampling scheme limited biological samples and exposure measurements to two days in the space of one week, so exposure windows greater than one week and lagged daily exposure effects could not be examined. Our reliance on microenvironmental samples, 

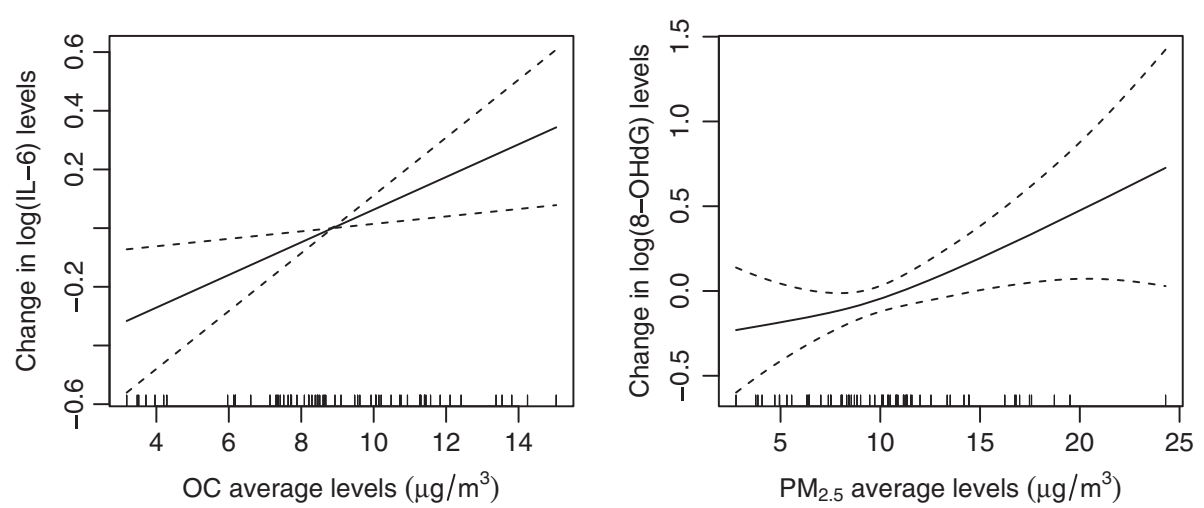

Figure 3 Exposure-response penalized spline term graphs. Associations between OC first and last-day average levels and IL-6 (left, effective degrees of freedom (edf) $=1, p=0.01$ ) and $\mathrm{PM}_{2.5}$ first and last-day average levels and 8-OHdG (right, edf =1.4, $\mathrm{p}=0.02$ ). Models adjusted for age, BMl, physical activity, hypertension, chronic disease, SHS exposure and in the case of IL-6 time varying medication use. (Dashed lines denote $95 \%$ Cls).

instead of personal samplers for each worker for each shift also likely lead to increased exposure misclassification. We also lacked information on exposures prior and between the shifts sampled. Exposures throughout the work week were not available for a significant portion of the study participants so average exposures over the entire week could not be considered. Additional limitations include limited power to detect modest effect sizes given the final sample size of non-smoking participants, number of measurements, and limited variability in exposures. Biomarker levels were measured with state of the art and highly sensitive methods. Pre- and post-shift samples were collected on the same time on the two sampling days, and statistical models included terms for time allowing variation but may not entirely capture within-person variation and diurnal patterns for these markers. Some non-differential misclassification may be expected, and could further reduce power to detect associations between an outcome and the exposures. Additionally, the study population is a generally healthy working male population so the findings may not be applicable to more sensitive or susceptible populations or to females.

The main strength of the current study was the concurrent assessment of microenvironment exposures and biomarker sampling in a study population with regular exposure to freshly generated exhaust, in levels that overlap with those seen in the general population. All sampled terminals were in the same company, with identical control technologies and al trucks were less than 5 years old, thus excluding potential sources of differential exposure misclassification across terminals. Additionally, we have previously shown that our microenvironment as defined by job description and location within a trucking terminal are highly representative of measured personal exposures in this industry [51].

\section{Conclusion}

Our findings suggest associations of a first and last workday average, but not daily occupational traffic related exposures with biomarkers of inflammation and oxidative stress. There was also evidence of different effects of separate components of PM on different biomarkers, specifically a $\mathrm{PM}_{2.5}$ effect on oxidative stress marker levels and an OC effect on inflammation marker IL-6 levels, indicating that different PM components may affect different biologic pathways.

\section{Abbreviations}

EC: Elemental carbon; OC: Organic carbon; $\mathrm{PM}_{2.5}$ : Particulate matter less than $2.5 \mu \mathrm{m}$ in diameter; ICAM-1: Intercellular adhesion molecule 1; VCAM1: Vascular cell adhesion molecule 1; IL-6: Interleukin 6; CRP: C-reactive protein; 8-OHdG: 8-Hydroxy-2'-Deoxyguanosine; IQR: Interquartile range; PM: Particulate matter; P\&D: Pick-up and delivery; PM $_{1.0}$ : Particulate matter less than $1.0 \mu \mathrm{m}$ in diameter; EDTA: Ethylenediaminetetraacetic acid; ELISA: Enzyme-linked immunosorbent assay; HPLC-ECD: High performance liquid chromatography with electrochemical detection; LOD: Level of detection; SHS: Second-hand smoke; BMI: Body mass index; SD: Standard deviation; GM: Geometric mean; GSD: Geometric standard deviation.

\section{Competing interests}

The authors declare no competing financial or non-financial interests.

\section{Authors' contributions}

AMN was responsible for analysis and interpretation of data and writing the manuscript. JEH assisted with design, data acquisition, analysis, and manuscript preparation. JC assisted with data acquisition and interpretation of data. TJS was involved in the study design and interpretation of data. DWD assisted with analysis, data interpretation and manuscript preparation. BAC assisted with analysis and data interpretation. EG was involved in study design and manuscript preparation. FL made contributions in conception, design, analysis and drafting the manuscript. All authors read and approved the final manuscript.

\section{Acknowledgments}

We thank Junfeng (Jim) Zhang, Marina J. Canner, Miguel Craig, Monica Zigman and William Roache for their contributions in the study.

The study was supported by the National Institute of Health/National Institute of Environmental Health Sciences grants R01 ES016284 and ESO00002. 


\section{Author details}

${ }^{1}$ Exposure Epidemiology and Risk Program, Department of Environmental Health, Harvard School of Public Heath, Boston, MA, USA. ${ }^{2}$ Channing Division of Network Medicine, Brigham and Women's Hospital and Harvard Medical School, Boston, MA, USA. ${ }^{3}$ Division of Occupational and Environmental Medicine, University of Connecticut Health Center, Farmington, CT, USA. ${ }^{4}$ Department of Biostatistics, Harvard School of Public Health, Boston, MA, USA. ${ }^{5}$ VA Boston Healthcare System, West Roxbury, MA, USA.

Received: 3 July 2013 Accepted: 4 December 2013

Published: 7 December 2013

\section{References}

1. Brook RD, Rajagopalan S, Pope CA 3rd, Brook JR, Bhatnagar A, Diez-Roux AV, Holquin F, Hong Y, Luepker RV, Mittleman MA, Peters A, Siscovick D, Smith SC Jr, Whitsel L, Kaufman JD, American Heart Association Council on Epidemiology and Prevention, Council on the Kidney in Cardiovascular Disease, and Council on Nutrition, Physical Activity and Metabolism: Particulate matter air pollution and cardiovascular disease: an update to the scientific statement from the American heart association. Circulation 2010, 121:2331-2378.

2. Dockery DW, Luttmann-Gibson H, Rich DQ, Link MS, Mittleman MA, Gold $D R$, Koutrakis P, Schwartz J, Verrier RL: Association of air pollution with increased incidence of ventricular tachyarrhythmias recorded by implanted cardioverter defibrillators. Environ Health Perspect 2005, 113:670-674.

3. Peters A, Dockery DW, Muller JE, Mittleman MA: Increased particulate air pollution and the triggering of myocardial infarction. Circulation 2001, 103:2810-2815.

4. Peters $\mathrm{A}$, von Klot $\mathrm{S}$, Heier M, Trentinaglia I, Hormann A, Wichmann HE, Löwel H, Cooperative Health Research in the Region of Augsburg Study Group: Exposure to traffic and the onset of myocardial infarction. N Engl $J$ Med 2004, 351:1721-1730.

5. Pope CA 3rd, Burnett RT, Thurston GD, Thun MJ, Calle EE, Krewski D, Godleski JJ: Cardiovascular mortality and long-term exposure to particulate air pollution: epidemiological evidence of general pathophysiological pathways of disease. Circulation 2004, 109:71-77.

6. Rich DQ, Kim MH, Turner JR, Mittleman MA, Schwartz J, Catalano PJ, Dockery DW: Association of ventricular arrhythmias detected by implantable cardioverter defibrillator and ambient air pollutants in Saint Louis, Missouri. Occup Environ Med 2006, 63:591-596.

7. Rich DQ, Schwartz J, Mittleman MA, Link M, Luttmann-Gibson H, Catalano PJ, Speizer FE, Dockery DW: Association of short-term ambient air pollution concentrations and ventricular arrhythmias. Am J Epidemiol 2005, 161:1123-1132.

8. Bigert C, Gustavsson P, Hallqvist J, Hogstedt C, Lewne M, Plato N, Reuterwal C, Schéele P: Myocardial infarction among professional drivers. Epidemiology 2003, 14:333-339.

9. Gustavsson P, Plato N, Hallqvist J, Hogstedt C, Lewne M, Reuterwall C, Schéele P: A population-based case-referent study of myocardial infarction and occupational exposure to motor exhaust, other combustion products, organic solvents, lead, and dynamite. Stockholm Heart Epidemiology Program (SHEEP) Study Group. Epidemiology 2001, 12:222-228

10. Hart JE, Garshick E, Smith TJ, Davis ME, Laden F: Ischaemic heart disease mortality and years of work in trucking industry workers. Occup Environ Med 2012 [Epub ahead of print].

11. Davis ME, Smith TJ, Laden F, Hart JE, Ryan LM, Garshick E: Modeling particle exposure in US trucking terminals. Environ Sci Technol 2006, 40:4226-4232.

12. Smith TJ, Davis ME, Reaser P, Natkin J, Hart JE, Laden F, Heft A, Garshick E: Overview of particulate exposures in the US trucking industry. J Environ Monit 2006, 8:711-720.

13. Chuang KJ, Chan CC, Su TC, Lee CT, Tang CS: The effect of urban air pollution on inflammation, oxidative stress, coagulation, and autonomic dysfunction in young adults. Am J Respir Crit Care Med 2007, 176:370-376.

14. Gurgueira SA, Lawrence J, Coull B, Krishna Murthy GG, González-Flecha B: Rapid increases in the steady-state concentration of reactive oxygen species in the lungs and heart after particulate air pollution inhalation. Environ Health Perspect 2002, 110:749-755.

15. Ren C, Fang S, Wright RO, Suh H, Schwartz J: Urinary 8-hydroxy-2'deoxyguanosine as a biomarker of oxidative DNA damage induced by ambient pollution in the Normative Aging Study. Occup Environ Med 2011, 68:562-569.

16. Rückerl R, Greven $S$, Ljungman $P$, Aalto $P$, Antoniades $C$, Bellander $T$, Berglind N, Chrysohoou C, Forastiere F, Jacquemin B, von Klot S, Koenig W, Küchenhoff H, Lanki T, Pekkanen J, Perucci CA, Schneider A, Sunyer J, Peters A, AIRGENE Study Group: Air pollution and inflammation (interleukin-6, C-reactive protein, fibrinogen) in myocardial infarction survivors. Environ Health Perspect 2007, 115:1072-1080.

17. Salvi S, Blomberg A, Rudell B, Kelly F, Sandstrom T, Holgate ST, Frew A: Acute inflammatory responses in the airways and peripheral blood after short-term exposure to diesel exhaust in healthy human volunteers. Am J Respir Crit Care Med 1999, 159:702-709.

18. Schwartz J: Air pollution and blood markers of cardiovascular risk Environ Health Perspect 2001, 109(Suppl 3):405-409.

19. van Eeden SF, Tan W, Suwa T, Mukae H, Terashima T, Fujii T, Qui D, Vincent R, Hogg JC: Cytokines involved in the systemic inflammatory response induced by exposure to particulate matter air pollutants (PM(10)). Am J Respir Crit Care Med 2001, 164:826-830.

20. Zeka A, Sullivan JR, Vokonas PS, Sparrow D, Schwartz J: Inflammatory markers and particulate air pollution: characterizing the pathway to disease. Int J Epidemiol 2006, 35:1347-1354.

21. Alexeeff SE, Coull BA, Gryparis A, Suh H, Sparrow D, Vokonas PS, Schwartz J: Medium-term exposure to traffic-related air pollution and markers of inflammation and endothelial function. Environ Health Perspect 2011, 119:481-486.

22. de Lemos JA, Hennekens $\mathrm{CH}$, Ridker PM: Plasma concentration of soluble vascular cell adhesion molecule-1 and subsequent cardiovascular risk. J Am Coll Cardiol 2000, 36:423-426.

23. Luc G, Arveiler D, Evans A, Amouyel P, Ferrieres J, Bard JM, Elkhalil L, Fruchart JC, Ducimetiere P, PRIME Study Group: Circulating soluble adhesion molecules ICAM-1 and VCAM-1 and incident coronary heart disease: the PRIME Study. Atherosclerosis 2003, 170:169-176.

24. Pradhan AD, Rifai N, Ridker PM: Soluble intercellular adhesion molecule-1, soluble vascular adhesion molecule-1, and the development of symptomatic peripheral arterial disease in men. Circulation 2002, 106:820-825

25. Pradhan AD, Manson JE, Rossouw JE, Siscovick DS, Mouton CP, Rifai N, Wallace RB, Jackson RD, Pettinger MB, Ridker PM: Inflammatory biomarkers, hormone replacement therapy, and incident coronary heart disease: prospective analysis from the Women's Health Initiative observational study. JAMA 2002, 288:980-987.

26. Ridker PM, Rifai N, Rose L, Buring JE, Cook NR: Comparison of C-reactive protein and low-density lipoprotein cholesterol levels in the prediction of first cardiovascular events. N Engl J Med 2002, 347:1557-1565.

27. Peters $\mathrm{A}$, Frohlich $\mathrm{M}$, Doring $\mathrm{A}$, Immervoll T, Wichmann HE, Hutchinson WL, Pepys MB, Koenig W: Particulate air pollution is associated with an acute phase response in men; results from the MONICA-Augsburg Study. Eur Heart J 2001, 22:1198-1204.

28. Rückerl R, Ibald-Mulli A, Koenig W, Schneider A, Woelke G, Cyrys J, Heinrich J, Marder V, Frampton M, Wichmann HE, Peters A: Air pollution and markers of inflammation and coagulation in patients with coronary heart disease. Am J Respir Crit Care Med 2006, 173:432-441.

29. Il'yasova D, Colbert LH, Harris TB, Newman AB, Bauer DC, Satterfield S, Kritchevsky SB: Circulating levels of inflammatory markers and cancer risk in the health aging and body composition cohort. Cancer Epidemiol Biomarkers Prev 2005, 14:2413-2418.

30. Siemes C, Visser LE, Coebergh JW, Splinter TA, Witteman JC, Uitterlinden AG, Hofman A, Pols HA, Stricker BH: C-reactive protein levels, variation in the C-reactive protein gene, and cancer risk: the Rotterdam study. J Clin Oncol 2006, 24:5216-5222.

31. Lagorio S, Tagesson C, Forastiere F, lavarone I, Axelson O, Carer A: Exposure tobenzene and urinary concentrations of 8-hydroxydeoxyguanosine, a biological marker of oxidative damage to DNA. Occup Environ Med 1994 51:739-743.

32. Kim JY, Mukherjee S, Ngo LC, Christiani DC: Urinary 8-Hydroxy-2'Deoxyguanosine as a biomarker of oxidative DNA damage in workers exposed to fine particulates. Environ Health Perspect 2004, 112:666-671.

33. Ren C, Vokonas PS, Suh H, Fang S, Christiani DC, Schwartz J: Effect modification of air pollution on urinary 8-Hydroxy-2'-Deoxyguanosine by genotypes: an application of the multiple testing procedure to identify significant SNP interactions. Environ Health 2010, 9:78. 
34. NIOSH: Elemental Carbon (Diesel Particulate) 5040. In NIOSH Manual of Analytical Methods. 4th edition. Edited by Casinelli ME, O'Connor PF. Ohio: National Institute for Occupational Safety and Health; 1998.

35. Tainio M, Tuomisto JT, Hanninen O, Aarnio P, Koistinen KJ, Jantunen MJ, Pekkanen J: Health effects caused by primary fine particulate matter (PM2.5) emitted from buses in the Helsinki metropolitan area, Finland. Risk Anal 2005, 25:151-160.

36. Yanosky JD, Maclntosh DL: A comparison of four gravimetric fine particle sampling methods. J Air Waste Manag Assoc 2001, 51:878-884.

37. Pai JK, Curhan GC, Cannuscio CC, Rifai N, Ridker PM, Rimm EB: Stability of novel plasma markers associated with cardiovascular disease: processing within 36 hours of specimen collection. Clin Chem 2002, 48:1781-1784.

38. Ferris BG: Epidemiology stamdardization project (American Thoracic Society). Am Rev Respir Dis 1978, 118:1-120.

39. Igishi T, Hitsuda Y, Kato K, Sako T, Burioka N, Yasuda K, Sano H, Shigeoka Y, Nakanishi H, Shimizu E: Elevated urinary 8-hydroxydeoxyguanosine, a biomarker of oxidative stress, and lack of association with antioxidant vitamins in chronic obstructive pulmonary disease. Respirology 2003, 8:455-460.

40. Pilger A, Germadnik D, Riedel K, Meger-Kossien I, Scherer G, Rüdiger HW: Longitudinal study of urinary 8-hydroxy-2'deoxyguanosine excretion in healthy adults. Free Radic Res 2001, 35:273-280.

41. Delfino RJ, Staimer N, Tjoa T, Gillen DL, Polidori A, Arhami M, Kleinman MT, Vaziri ND, Longhurst J, Sioutas C: Air pollution exposures and circulating biomarkers of effect in a susceptible population: clues to potential causal component mixtures and mechanisms. Environ Health Perspect 2009, 117:1232-1238.

42. Dubowsky SD, Suh H, Schwartz J, Coull BA, Gold DR: Diabetes, obesity, and hypertension may enhance associations between air pollution and markers of systemic inflammation. Environ Health Perspect 2006, 114:992-998.

43. Forbes LJ, Patel MD, Rudnicka AR, Cook DG, Bush T, Stedman JR, Whincup $\mathrm{PH}$, Strachan DP, Anderson RH: Chronic exposure to outdoor air pollution and markers of systemic inflammation. Epidemiology 2009, 20:245-253.

44. Steinvil A, Kordova-Biezuner L, Shapira I, Berliner S, Rogowski O: Short-term exposure to air pollution and inflammation-sensitive biomarkers. Environ Res 2008, 106:51-61.

45. Riediker M, Cascio WE, Griggs TR, Herbst MC, Bromberg PA, Neas L, Williams RW, Devlin RB: Particulate matter exposure in cars is associated with cardiovascular effects in healthy young men. Am J Respir Crit Care Med 2004, 169:934-940.

46. Li Y, Rittenhouse-Olson K, Scheider WL, Mu L: Effect of particulate matter air pollution on C-reactive protein: a review of epidemiologic studies. Rev Environ Health 2012, 27:133-149.

47. Bind MA, Baccarelli A, Zanobetti A, Tarantini L, Suh H, Vokonas P, Schwartz J: Air pollution and markers of coagulation, inflammation, and endothelial function. Epidemiology 2012, 23:332-340.

48. Stenfors N, Nordenhäll C, Salvi SS, Mudway I, Söderberg M, Blomberg A, Helleday R, Levin JO, Holgate ST, Kelly FJ, Frew AJ, Sandström T: Different airway inflammatory responses in asthmatic and healthy humans exposed to diesel. Eur Respir 」 2004, 23:82-86

49. Madrigano J, Baccarelli A, Wright RO, Suh H, Sparrow D, Vokonas PS, Schwartz J: Air pollution, obesity, genes and cellular adhesion molecules. Occup Environ Med 2010, 67:312-317.

50. Wang Y, Hopke PK, Rattigan OV, Chalupa DC, Utell MJ: Multiple-year black carbon measurements and source apprtionement using Delta-C in Rochester, New York. J Air Waste Manag Assoc 2012, 62:880-887.

51. Davis ME, Hart JE, Laden F, Garshick E, Smith TJ: A retrospective assessment of occupational exposure to elemental carbon in the U.S. trucking industry. Environ Health Perspect 2011, 119:997-1002.

doi:10.1186/1476-069X-12-105

Cite this article as: Neophytou et al:: Traffic-related exposures and biomarkers of systemic inflammation, endothelial activation and oxidative stress: a panel study in the US trucking industry. Environmental Health 2013 12:105.

\section{Submit your next manuscript to BioMed Central and take full advantage of:}

- Convenient online submission

- Thorough peer review

- No space constraints or color figure charges

- Immediate publication on acceptance

- Inclusion in PubMed, CAS, Scopus and Google Scholar

- Research which is freely available for redistribution

Submit your manuscript at www.biomedcentral.com/submit 